\title{
SPATIO-TEMPORAL ANALYSIS OF LAND USE DYNAMICS AND ITS POTENTIAL IMPLICATIONS ON LAND SURFACE TEMPERATURE IN LAHORE DISTRICT, PUNJAB, PAKISTAN
}

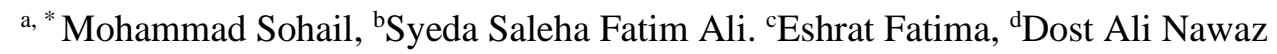 \\ ${ }^{\mathrm{a}}$ Centre for Water Informatics and Technology, LUMS, Pakistan, ${ }^{\mathrm{b}}$ National Agriculture Robotic Laboratory, LUMS, Pakistan, \\ ${ }^{\mathrm{c}}$ University of Potsdam, Germany, ${ }^{\mathrm{d}}$ Snow Leopard Foundation, Pakistan
}

KEY WORDS: Land use/ land cover, Land surface Temperature, Spatio-temporal analysis, Classification Accuracy Assessment, Remote Sensing, GIS.

\begin{abstract}
:
The rapid population growth and the urge in people to move to big cities for their settlement upshot in urban expansion. While stepping into the corridor of the $21^{\text {st }}$ century, the utility of remote sensing and GIS techniques in various fields has made things understandable and thus enhances the ways of investigation for better decision making and management. The paper presents the Landsat Satellite series based Land Surface Temperature retrieval concerning land use/ land cover changes over Lahore District, Punjab, Pakistan. The Spatio-temporal analysis was performed from 1980-2020. We availed high-resolution Landsat and Sentinel-2 Satellite imagery to perform Normalized Difference Vegetation Index and Supervised classification. Cloud-free satellite data was acquired from June, July, or August. Data pre-processing including atmospheric and terrain corrections were performed using ERDAS Imagine. The Red, NIR, and Thermal bands were utilized for LST estimation. ArcGIS 10.22 was used for making maps, analysis, and interpretations. The Spatio-temporal analysis of LULC and LST for the area indicates a great urbanization trend over the past forty years. People are migrating from small towns and villages to the metropolitan city of Pakistan for their livelihoods, and settlements. The built-up/urban land has expanded over the period with excessive construction that has affected the Land surface temperature. The area where human activity has increased shows higher LST's as compared to green lands. The excessive construction has taken off the agricultural land, while the River Ravi still flows with a changing course and less water table. The COVID-19 pandemic hit in 2020 put everything on lockdown had an impact on environmental restoration due to fewer emissions and human activities. The overall classification accuracy of the images yielded substantial-high Kappa statistics of $80 \%, 88 \%, 82 \%$, $82.41 \%$, and $87.76 \%$ for $1980,1990,2000,2010$, and the 2020 images, respectively. The unplanned urbanization is leading the Lahore District to serious environmental issues and climate change impacts. The need of the hour is to properly plan and manage the area for the coming generations to have a healthier and sustainable place to breathe in.
\end{abstract}

\section{INTRODUCTION AND LITERATURE REVIEW}

The rapid urban expansion and shrinking of green lands because of population growth are serious concerns in developing countries (Jarah et al., 2019). With this, the changing climate globally also contributes when it comes to overall environmental conditions (Akanwa et al., 2019). Pakistan is a country that has faced great climate change and global warming hit (Khan et al., 2016). Out of these odds, the extensive urbanization played as an add-on to impact the overall weather (Liu et al., 2020).

Estimation of land use/land cover plays a vital role when appraising the impact of urban culture and its potential influence on temperature (Ding et al., 2013, Sadiq Khan et al., 2020). Land cover is the natural type of feature on the Earth, like vegetation, waterbody, soil, rock, etc. (Hassan et al., 2016). Whereas, if some activity is associated with the land cover for our use, is land use (Hussain et al., 1019, Alawamy et al., 2020). We have to consider the existing land use pattern, and how and why it may be planned and assessed to have a sustained environment (Shakrullah et al., 2019). Thus, utilizing the land cover in a way that may not impact the environment and the health of the individuals is very important, and should be done efficiently and ethically (Cengiz 2013). Earlier conventional estimation methods were chain surveying,

*sohaiskhan@gmail.com old mechanical theodolites, vernier theodolites, paper maps, but now we use remote sensing, Geographic Information System (GIS), Global Positioning System (GPS), total station, etc. (Osborne et al., 2012). These modern methods have improved the accuracy and the asset of making thematic observations (Reis 2008).

The usefulness of remote sensing techniques and GIS abilities has been ranked higher in the last few decades (Ali et al., 2019). Now, high-resolution satellite imagery is available which is very useful for various environmental applications (Chengqi et al., 2003). There are various features on the land. Arranging them into classes according to activity is significant, and comes out as "land use/land cover classification" (Deng et al., 2019). Hard classification is generally pixel-based and governs the resolution. Smaller pixel size has higher resolution and vice versa. We assign a class label to the pixel and the digital number value is classified based on spectral signatures. Whereas, in soft classification, fuzzy logic is adopted and is very useful to accommodate the mixed pixel issues (Luna et al., 2006).

The satellite imagery is chosen based on its application. For instance, based on land use/land cover classification, our ultimate goal is to know its impact on Land Surface Temperature (Aik et al., 2020). For this, we need to select the imagery of a season when we can get all the classes. The LST on vegetation and the built-up area may be estimated, and its 
potential impacts may be identified. We need to understand what the land use/ land cover map depicts, i.e., vegetation, built-up, waterbody, barren land, etc. (Pal et al., 2017).

There is an ambient air temperature which we are familiar with, but the Land Surface Temperature does not come quite often (Liu et al., 2017). The surface materials possess some qualities, and based on those characteristics, have a surface temperature. It is the skin temperature of the ground. It is important because we all are familiar with the very fact that climate is changing and is linked with both the atmospheric as well as surface factors and their interactions (Hofmann et al., 2017). LST is an important input to climate models (Ali et al., 2019). Understanding the past and current conditions, we can model the future through climate modeling (Sillmann et al., 2017).

LST is the key factor controlling the earth's surface and the atmosphere interplay (Weng et al., 2004). Urban concrete jungles are emerging thus impacting the weather patterns (Weng et al., 2004). LU/LC classification and LST can be estimated through RS tools using Visible and Thermal Bands (Wang et al., 2020). The earth's radiant temperature is dependent on two major factors (Xiao et al., 2008), Temperature, and Emissivity. Temperature is the ground surface kinetic temperature that depends on the heat energy budget and the thermal property of the material, whereas Emissivity $€$ is the property of the material controlling the radiant energy flux based on color, solar radiation, the surface state of the object, etc. (Xiao et al., 2008).

The RS satellites help in getting the reflected radiation from different objects, and a spectral response can be seen on the electromagnetic spectrum (Figure 1).

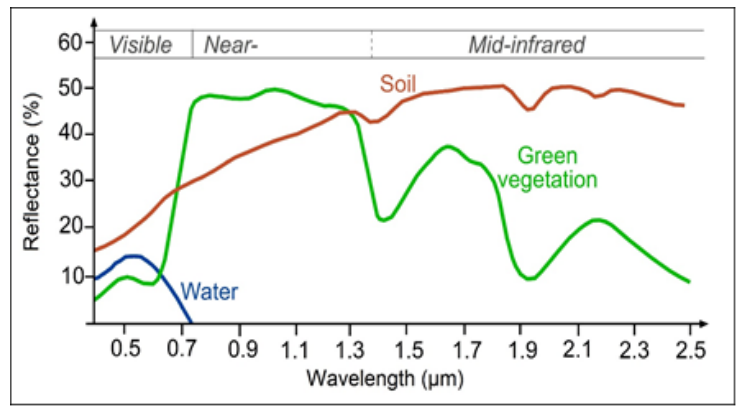

Figure 1. The spectral signatures of different LU/LC types through the electromagnetic spectrum.

Various studies have estimated the land use/ land cover changes and Land Surface Temperatures and elaborated the different factors that influence them. Mahesh et. al 2017, Azad et. al 2018 classified the built-up areas and bare soil based on different indices including (Normalized Built-up Area Index; NBAI, Band Ratio for Built-up Area; BRBA, and Bare Soil Index; BSI). Nasar-u-Minallah 2019, did a one-time estimation of LST for Lahore using Landsat 8 OLI. Zarnain et. Al 2020 used a mixed-method approach that included geospatial and statistical analysis to appraise the built-up area extraction with a growing population for Lahore from 1996-2015. Ather et, al 2015 indicated the agricultural land degradation between 20092012 using indices and statistical methods for Lahore. Anum et, al 2018 analyzed the impact of urban growth for Gujranwala City, Punjab, Pakistan from 2003-2018. (Saleem et al., 2020) worked on the impacts of changing built-up areas over three districts of Punjab province, Pakistan from 1998-2017.
The research focuses on the impacts of urban development on land surface temperature in the past forty years. The study objectives cater to the land use/land cover classification using remotely sensed data, the land surface temperature estimation using visible and thermal Landsat satellite series bands, and the assessment of LU/LC change on LST in the past forty years for a historic and densely populated city of Punjab Province in Pakistan i.e Lahore.

\section{STUDY AREA}

The second-largest metropolitan city of Pakistan after Karachi is covering an area of $1,772 \mathrm{~km}^{2}(684 \mathrm{sq} \mathrm{mi})$ at an above sea level elevation of 217 meters (Nasar-uMinallah, 2019, GoP), Lahore stretches from $31^{\circ} 15^{\prime} 31^{\circ} 43^{\prime} \mathrm{N}$ through $74^{\circ} 10^{\prime}-74^{\circ} 39^{\prime} \mathrm{E}$ With the densely populated areas, it is hosting one of five rivers of the Punjab province, the River Ravi. The Lahore city has expanded in the last decades with massive urban culture and the surrounding agricultural lands have also been transformed into built-up areas for the sake of a better future and settlements by the individuals. An extreme climate is faced by the residents especially during the summer months (April - September) (Zarnain et al., 2020), having June-July being the hottest. The average minimum and maximum atmospheric temperatures recorded are $29.3^{\circ} \mathrm{C}$ and $45.4^{\circ} \mathrm{C}$ respectively for these months. Winter starts unveiling in mid of October and goes until March. December to February are the coldest months (GoP, 2000). Holding up the population of around 12,642,423 individuals as estimated in 2020. The massive urban expansion with a growing population is leading the Capital city of the Punjab province to serious environmental risks like the smog that is being faced in recent years. The city is a rich cultural bunch and has hosted major rules i.e the Mughals, the British Colonials, and the Modern Era.

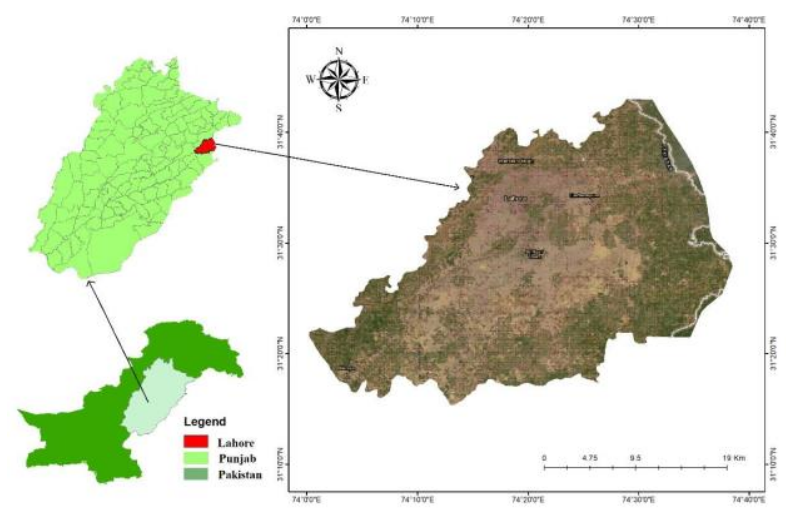

Figure 2. Study Area Map

\section{WORKING METHODOLOGY}

\subsection{Datasets}

Table 1 presents the detailed description of satellite data used in the analysis which include: Landsat L-3 MultiSpectral Scanner for the year 1980, L-5 Thematic Mapper for 1990, L-7 Enhanced Thematic Mapper for 2000, and 2010 while L-8 Operational Land Imager (OLI) and Thermal Infrared Sensor (TIRS) image for 2020, acquired from the archives of United States Geological Survey (USGS). The images composed of pixels at $30 \mathrm{~m}$ resolution, were processed according to the calibration technique proposed by (Chander et al., 2009) to convert digital number values to at-sensor spectral radiance 
values. Atmospheric correction of the TM reflective bands and computation of the surface reflectance was performed using the Chavez method (Chavez, 1996), which requires only data from the same satellite scenes, without needing contemporary in-situ measurements (Cui et al., 2014).

The following flow chart describes the overall processes that are included in the research. The Landsat images and the DEM were exported to the ERDAS 2014 software and used for preand postprocessing such as layer stacking, clipping atmospheric and topographic correction of satellite imageries, and ArcGIS 10.2 for further analysis,

\begin{tabular}{|l|l|l|l|}
\hline Acquisition & Satellite & Sensor & Path/Row \\
\hline Aug 1980 & Landsat 3 & MSS & $149 / 38$ \\
\hline Aug 1990 & Landsat 5 & TM & $149 / 38$ \\
\hline Aug 2000 & Landsat 7 & TM & $149 / 38$ \\
\hline Aug 2010 & Landsat 5 & ETM+ & $149 / 38$ \\
\hline Jun 2020 & Landsat 8 & OLI/TIRS & $149 / 38$ \\
\hline
\end{tabular}

Table 1. Datasets Used.

\subsection{Data Processing}

The spatial, resolution of the Landsat satellite data offers reliable, relatively consistent, and proper resolve information that is important for the assessment of vegetation cover changes that occur with time. Several corrections should be made to remotely sense data after being acquired reduces its efficiency of obtaining information and quality of satellite imageries. Consequently, the image (pre and post) processing of remotely sensed data before proceeding to actual interpretation and analysis is essential. Commercial data provider usually eliminates systematic geometric distortion and radiometric errors of Landsat data. In pre-processing mainly layer stacking and mosaic of satellite imageries were done. The study area is covered in only one scene so, no mosaicking was needed. ERDAS is used for the layer stacking of different bands of Landsat imageries of 1980, 1990, 2000, 2010, and 2020.

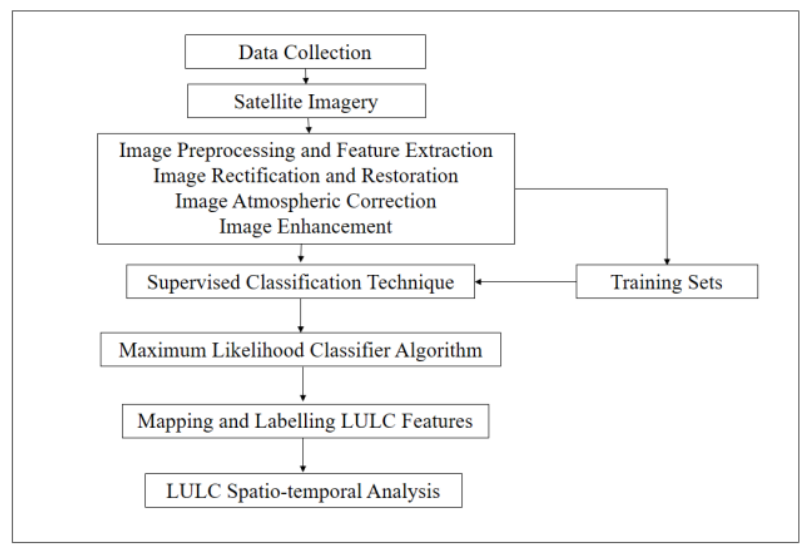

Figure 3. Working Methodology- Land use/ Land Cover Classification.

\subsubsection{Layer Stacking and Clipping}

Before clipping, satellite imageries of 1980, 1990, 2000, 2010, and 2020 which consist of different bands were stacked into a composite image, and projection transformation was carried out by using UTM WGS-84 projection. After layer stacking from imageries of Landsat satellites, the area of interest was clipped by using the clip option in the ArcGIS environment.

\subsubsection{Digital Elevation Model (DEM)}

DEM stores information of continuously varying variables like elevation, ground depth, and water depth, etc. The

Digital Elevation Model DEM of Shuttle Radar Topographic Mission at a special resolution of $30 \mathrm{~m}$ was used to obtain slope, aspect, and hillside images for atmospheric correction. The spatial resolution of DEM (SRTM) used for correction must equal to the spatial resolution of the other raster dataset the cell size and scale must be the same as the other dataset use for the correction process.

\subsubsection{Atmospheric Correction}

Higher to a moderate resolution of optical satellite data is one of the important and valuable sources for the different fields of studies and research like natural resources management, environmental conservation, etc. But unfortunately, effects like the atmospheric effect can increases inaccuracy in the classification of land cover analysis and have an impact on the quality of imageries during the acquisition of satellite data. In cases where multi-temporal, multi-sensor or multi-spectral images are used, such a correction is very important and useful for interpretation and estimation of land cover.

To extract meaningful information from Landsat and Sentinel 2 imagery, the atmospheric correction was performed using the PCI Geomatica (an image processing software) for satellite imageries of 1980, 1990, 2000, 2010, and 2020 periodically. The Visible (Red, green, blue), NIR (near-infrared), and SWIR short-wave infrared) bands for Landsat MSS, Landsat TM, and Landsat OLI were imported and pre-processed.

\subsubsection{Normalized Difference Vegetation Index (NDVI)}

Normalized Difference Vegetation Index estimation is the next step as it categorizes the variation in vegetation cover from the water body, rocky areas, barren land to dense vegetation $(-0.1-$ 0.1). NDVI was introduced by roused et al. (1974) for differentiating green vegetation from its background soil brightness using Satellite images. It is expressed as the difference between the near-infrared and red bands normalized by the sum of those bands. The highest value of the NDVI indicates forest and the lowest value indicates no or less vegetation. In this study, the NDVI is used to understand the distribution of vegetation throughout the study area, which is significant for enhancing the accuracy of forest and woodland classification change. Thus, NDVI above 0.51 is considered high to very high vegetation cover.

$$
\text { NDVI }=(\text { NIR }- \text { RED }) /(\text { NIR }+ \text { RED })
$$

NIR and RED are the DN reflectance from near-infrared and red bands, respectively

NDVI $=-0.1$ to $0.1-$ Barren rocks, sand, or snow

$\mathrm{NDVI}=0.2$ to 0.5 - Shrubs and grasslands or senescing crops 


\subsubsection{Supervised Image classification processing}

The land cover/land use type information can be mined using the supervised classification technique. The homogenous land covers are specified by the image analyst based on his local geographical location's knowledge. The computer uses a special program or algorithm (of which there are several variations), to determine the numerical "signatures" for each training class.

A maximum-likelihood algorithm was applied to develop the land cover. Based on the training areas and the spectral signature, the cover map with 5 different classes, which were finally lumped together and re-coded into six classes according to the classification scheme. Signatures for 1980, 1990, 2000, 2010, and 2020 satellite images were generated to extract each land cover type to avoid biases. Once each site was identified in the combined image, signatures were stacked in each Landsat image for supervised classification using the maximum likelihood classification method.

\subsection{Land Surface Temperature}

Cloud free Landsat satellite series data (Deng and $\mathrm{Wu}, 2013$ ) from 1980 through 2020 were downloaded, and protrude on the Universal Transverse Mercator (UTM) projection along with WGS84 datum and zone 43North and pre-processed. The data type and file formats were integer and Tagged Image File Format (TIFF) respectively. The vector layer as shapefile was used to extract the Lahore district administrative boundary as the area of interest (AOI) from the scene.

The LST was estimated using the corrected Landsat 5 Satellite imageries for 1990, 2000, and Landsat 7 for 2010 from the Thermal IR bands (10.44-12.42 micro-m). Having a $30 \mathrm{~m}$ spatial resolution, the well-calibrated imagery has a revisit time in the morning. The algorithm in ERDAS IMAGINE 2014, allows the Modelmaker to create a model that may be used several times, easy to develop, and useful for doing pixel calculations. This tool helps in LST retrieval precisely and efficiently.

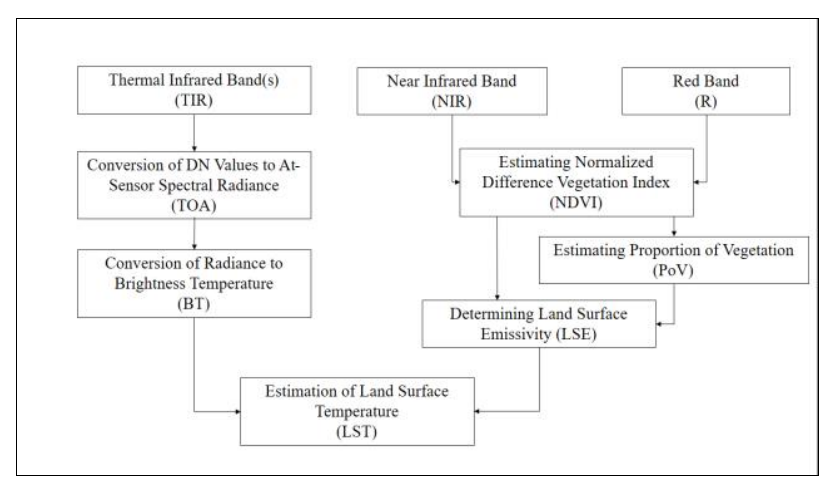

Figure 4. Working Methodology-Land Surface Temperature Estimation.

To convert the Landsat ETM+ TIR band digital number (DN) into spectral radiance, we took the help of the following equation:

$$
\mathrm{L} \lambda=\mathbf{0 . 0 3 7 0 5 8 8} * \mathrm{DN}+3.2(2)
$$

To estimate the Land Surface Temperature of Lahore District, Punjab, Pakistan, from Landsat 8 spectral bands, the thermal infrared (TIR) bands 10 and 11 were utilized to estimate brightness temperature, and OLI optical bands red-4 and near infrared-5 were utilized to produce NDVI of the study area. Thermal constant and rescaling factor values of thermal bands have been provided by the Landsat- 8 satellite. For Landsat 8 , because of the data complexity, ArcMap 10.2 was used instead of the ERDAS IMAGINE 2014 model builder. Following methodology was adopted to retrieve the LST using Landsat 8 Spectral bands:

The first step of the algorithm is the input of Thermal Infrared Band 10 and Band 11. After inputting bands, in the background, the tool uses formulas taken from the USGS webpage for retrieving the top of atmospheric (TOA) spectral radiance.

$$
\mathrm{TOA}=\mathbf{0 . 0 0 0 3 3 4 2} * \text { "DN" }+0.1
$$

According to USGS defined methodology, the next step is to convert the Top of Atmosphere spectral radiance to at satellite brightness temperature (i.e., blackbody temperature, BT) under the assumption of uniform emissivity (Landsat Project Science Office, 2002). The conversion formula is:

$$
\mathrm{BT}=(\mathrm{K} 2 /(\ln (\mathrm{K} 1 / \mathrm{L})+1))-273.15
$$

Where

BT (Satellite Brightness Temperature)

$\mathrm{K} 2$ and $\mathrm{K} 1$ Band-specific thermal conversion constant (metadata file).

$\mathrm{K} 1$ (W m-2 sr-1 $\mu \mathrm{m}-1)$

K2 (Kelvin)

273.15 factor is subtracted to get the BT in Celsius.

As the proportion of vegetation cover $(\mathrm{PoV})$ is a parameter when estimating the LST, the next step involves Normalized Difference Vegetation Index estimation to get the PoV that may be utilized further. The description of NDVI is elaborated in section 3.2.5.

The Proportion of Vegetation is estimated as suggested using the NDVI values.

$$
\text { PoV }=\left(\text { NDVI }- \text { NDVI }_{\min }\right) /\left(\text { NDVI }_{\max }-\text { NDVI }_{\min }\right)^{2}
$$

Where

PoV is the proportion of vegetation.

NDVI is the Raster Image of NDVI

NDVI max -represents NDVI maximum pixel value

NDVI min - minimum NDVI pixel value

Usually, the minimum and maximum values of the NDVI image can be displayed directly in the image, or one can see the spectral signature histogram and find the maximum and minimum values.

The land surface emissivity (LSE) must be known to estimate LST, since the LSE is a proportionality factor that scales blackbody radiance (Planck's law) to predict emitted radiance, and it is the efficiency of transmitting thermal energy across the surface into the atmosphere. It is given by: 


$$
\varepsilon=0.004 * \mathrm{PoV}+0.98 \text { (6) }
$$

Where PoV is the proportion of vegetation.

Finally, to obtain the land surface temperature map, the last step is applied.

The emissivity corrected land surface temperature is computed as follows.

$$
\mathrm{LST}=(\mathrm{BT} /(1+(0.00115 * \mathrm{BT} / 1.4388) * \operatorname{In}(\varepsilon)))
$$

Where

\section{LST- Land Surface Temperature}

\subsection{ACCURACY ASSESSMENT}

The accuracy \& precision of the image classification is a verified method of stratified random sampling and utilization of the reference ground data composed of the fieldwork and land use base map of Lahore. To increase the accuracy of land use mapping of the two image data sets, supplementary data and the result of visual interpretation were incorporated with the image Classification result using RS \& GIS techniques to increase the image classification accuracy assessment of the classified image. Standard overall classification accuracy for land use maps is set between 85 and 90 percent. Random sample techniques used for accuracy assessment, which aims to quantitatively assess how effectively the pixels were sampled into the correct land cover classes. Besides the main importance for accuracy assessment pixel selection was on areas that could be identified on both Landsat and high-resolution images, like Google earth. A total of 100 points (locations) were created in the classified image of the study area. Thus, the statistical value of the overall accuracy, kappa coefficient, omission error (producer's accuracy), and commission error (user's accuracy) was computed for the 1980s, 1990, 2000, 2010, and 2020. The kappa statistics showed the probability of an agreement that could be expected to present by chance (Ghebrezgabher et al. 2016). Where the value ranges from +1.0 to -1.0 . For positive value, kappa statistics show strong strength of agreement while on another hand negative value indicates poor strength of agreement. Kappa analysis is a discrete multivariate technique used in accuracy assessments. Kappa analysis yields Kappa statistics(an estimate of KAPPA) that is a measure of agreement or accuracy (Rwanga and Ndambuki 2017). The Kappa statistic is computed as;

$$
K=\frac{N \sum_{i=1}^{r} x_{i i}-\sum_{i=1}^{r}\left(x_{i}+X x_{+1}\right)}{N^{2}-\sum_{i=1}^{r}\left(x_{i i} X x_{+1}\right)}
$$

Where

$\mathrm{r}=$ number of rows and columns in the error matrix

$\mathrm{N}=$ total number of observations (pixels)

Xii $=$ observation in row $\mathrm{i}$ and column $\mathrm{i}$

$\mathrm{Xi}+=$ marginal total of row $\mathrm{I}$

\begin{tabular}{|l|l|l|}
\hline Sr. No. & Kappa statistics & Strength of agreement \\
\hline 1 & $<0.00$ & Poor \\
\hline 2 & $0.00-0.20$ & Slight \\
\hline 3 & $0.21-0.40$ & Fair \\
\hline 4 & $0.41-0.60$ & Moderate \\
\hline 5 & $0.61-0.80$ & Substantial \\
\hline 6 & $0.81-1.00$ & Almost perfect \\
\hline
\end{tabular}

Table 2. Rating Criteria Of Kappa Statistics.

\section{RESULTS AND DISCUSSION}

\subsection{Spatio-temporal Analysis of Land use/land cover}

Land use/ land cover classification was performed using the supervised classification technique. For this, Landsat cloud-free Satellite Imageries were acquired from the United States Geological Survey data hub for June, July, or August for the years 1980, 1990, 2000, 2010, 2020, based on the data availability. The figure below shows a detailed Spatio-temporal land use/ land cover change. A degradation in green lands/ vegetation is observed from 1980 through 2020. The imagery differentiates five different categories or classes namely water, barren, agriculture, built-up, trees, respectively. It is evident in the results that the urban/built-up areas have been increased with population growth and the need for urban expansion.

The time series analysis of these spatial datasets shows a changing pattern in Lahore District from 1980-2020. Comparing the imagery, a river channel i.e the River Ravi flows in the Northeast to Southwest direction. With time, we can detect the changing river course due to urban expansion in the area, and the encroachments along the Riverside.

In the LULC map below, in 1980, we see very little built-up or urban land. Most of the area is covered with agriculture or green lands. The urban areas can be seen on the North-western side, with very less barren land on the South-western part, and trees can be seen on the Northeastern regions of the Lahore District (figure 5, a).

Only within ten years in 1990 , the urban culture seems to be increased. We can notice the urban areas been expanding around the river Ravi Northwest of the study area. We can spot the trees with the expanding urban land too, which shows that despite the urge in people to enjoy urban culture, they were environment friendly and prone to grow trees wherever they settled. With this, a degradation in agriculture is visible in the central and south-western parts of the Lahore District (Figure 5, b).

As we stepped into the corridors of the 21 st century, the urban population is increased in the area, with almost sillier growth in the barren land. We can spot the trees here as well and decreasing trend of the agriculture or green land. It is noticeable here that the urban culture was concentrated on the Northwestern regions of Lahore District uptilt 2000 (figure 5, c).

Just after a decade after we entered the new century. in 2010, we can observe that the urban growth is expanding spatially. The South-western regions which were barren back then were 


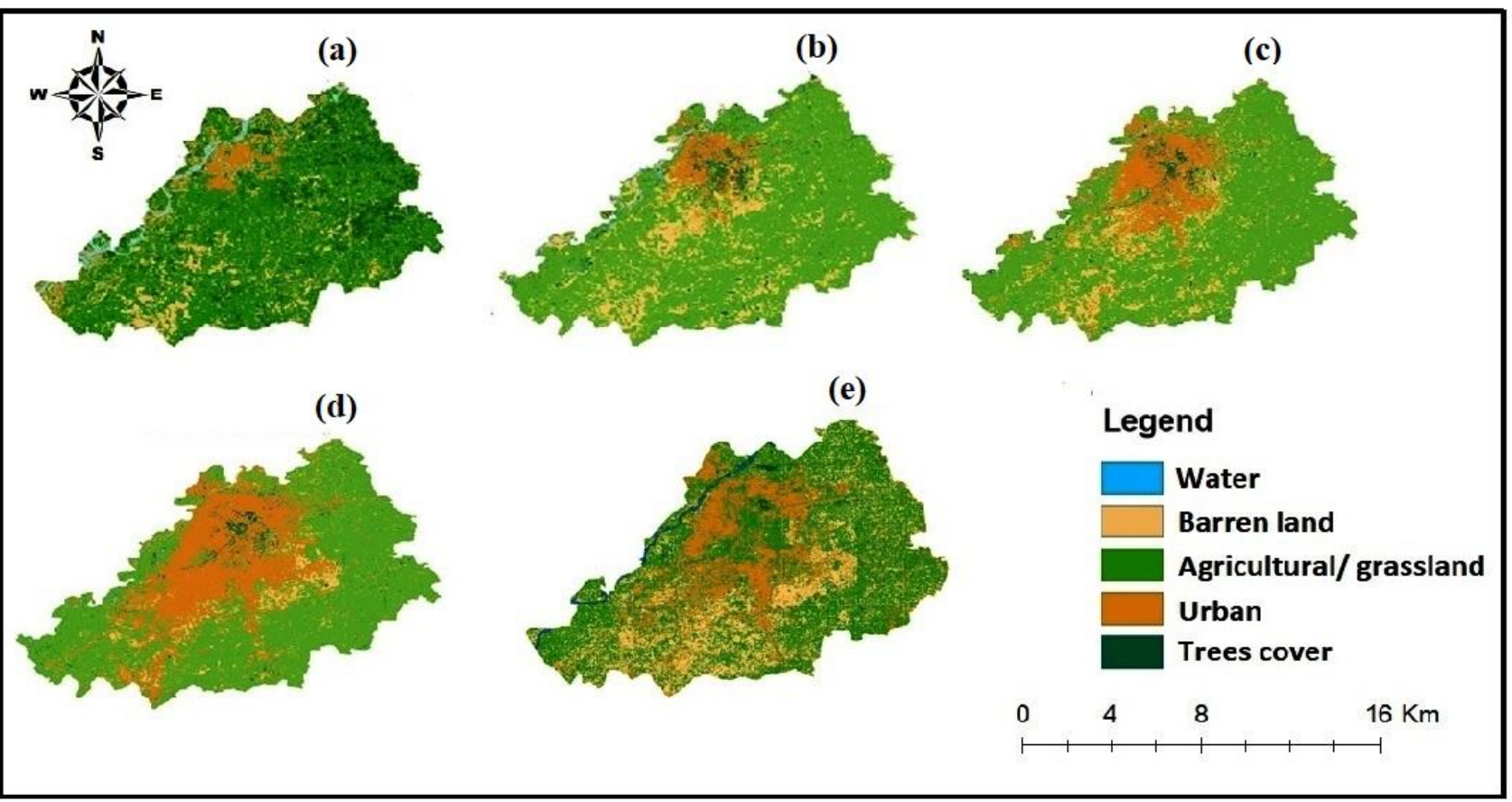

Figure 5. Spatio-temporal Analysis of Land use/land cover (1980-2020).

utilized for urban development within ten years for the population settlement. Environmental degradation is also perceived with the decrease in plantation (figure 5,d).

A substantial increase in urbanization is observed in 2020 . (Figure 5, e) depicts an overall urban /built-up spread. With this, it can be noticed that the plantation trend is also prevailing throughout the Lahore District, and is a good indicator of environmental restoration. This indicates an increasing trend of urbanization which may cause a major decrease in the primary agricultural/green land in the Lahore District in the future.

\subsection{Spatio-temporal Analysis of Land Surface Temperature}

The Spatio-temporal analysis of Land Surface Temperature is imperative when appraising the impact of population growth on urban expansion. Land Surface Temperature (LST) was estimated to appraise how the increasing population has and urban activities influenced the overall environment of the Lahore District. For this, Landsat Satellite cloud-free imagery from the same months June, July, or August for the years 1990, 2000, 2010, and 2020, was acquired from the US Geological Survey data hub. The data was selected as the Landsat Satellite series contains Thermal bands that are the main source for estimating the LST.

In figure 6, it can be noted that a temperature pattern exists. For instance, along with the River Ravi, the Northwest part of the Lahore District, the temperature seems to be lower as compared to the built-up/urban regions where there exist human activities. Similarly, the regions having agriculture/ greenery, or trees have lower temperatures, while the barren or urban areas have more temperatures.

A spatial pattern can be seen with land use/ land cover change going from 1990 (figure 6, a). As we stepped into the 21st century, the changing temperature is clear with the increasing urbanization and population growth. It can be seen that the temperatures are higher in built-up and barren regions. A higher temperature pattern is observed from Northeast to Southwest (figure 6, b).

The increase in Land Surface Temperature was just a matter of ten years after the new century of development commenced. The spatial pattern depicts that the temperature is increasing in the Lahore District due to an increased population, and the requirement for urbanization. People are moving to big cities for their livelihoods and settlements (figure $6 \mathrm{c}$ ).

To appraise the Spatio-temporal variation in LST between 2010 and 2020, we estimated the LST for the year 2018. The excessive construction in the Lahore District has led to temperature increases and decreasing green lands. In 2010, the changes in LULC have influenced the average temperature is shown in figure $(6, d)$. From the analysis, it was concluded that maximum temperature was increased in an urban area from 2000 to 2010 as compared to other land covers. In water bodies and trees, the minimum changes occur in the land surface temperature of the study area.

As we are familiar with the very fact, the recent COVID-19 pandemic hit the world badly. Yet, it ended up well for the environmental restoration. It can be noticed in the LST's spatial pattern for the year 2020 (figure 6, e). Due to the complete lockdown situation globally, there were almost no to very little human activities in Lahore District as well. The emissions were very less, lowing the pollution, hence decreasing the LST spatially and higher temperature a degree lower.

Greenery and agricultural land cover show also significant changes in surface temperature. The analysis and interpretation of land surface temperature indicate that major changes in land surface temperature occur from 1990 to 2020. 


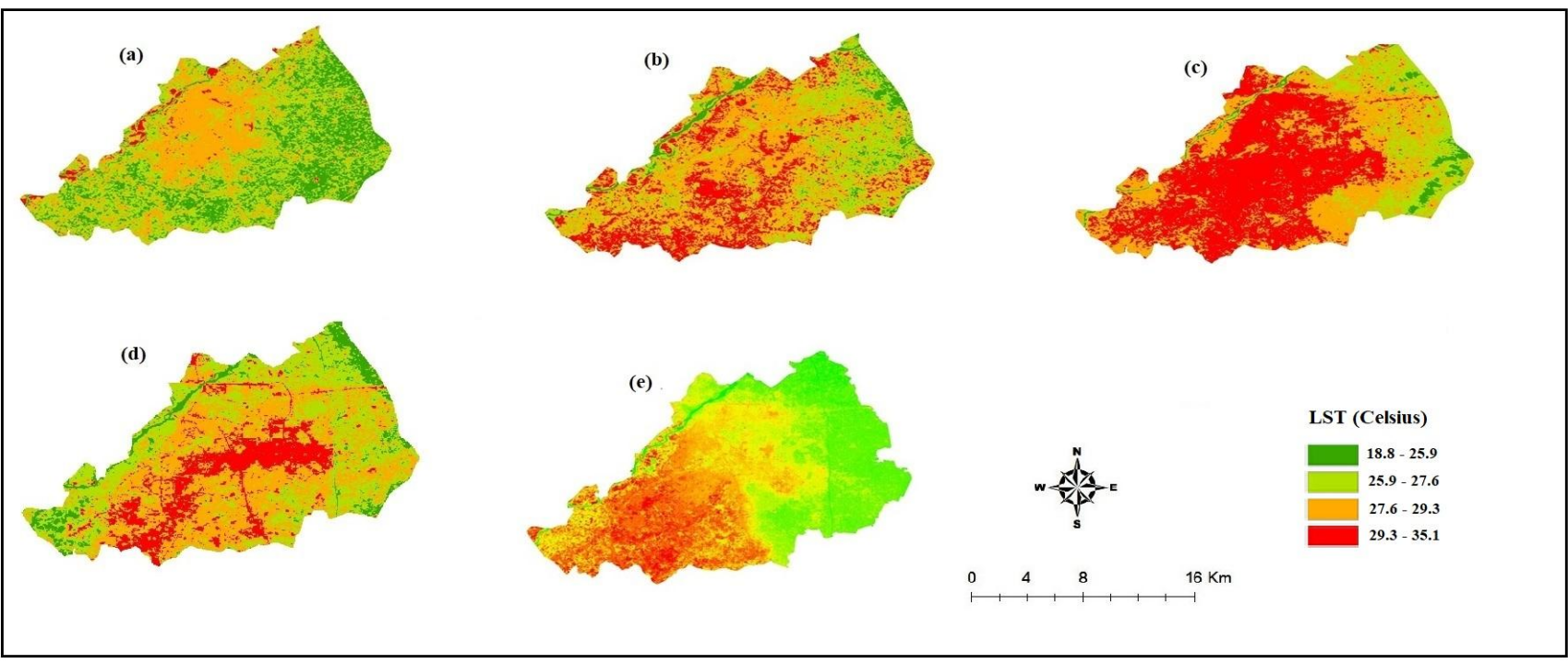

Figure 6. Spatio-temporal Analysis of Land Surface Temperature (1980-2020).

\subsection{Classification Accuracy Assessment}

One of the most important steps in the classification process is to determine the quality of information derived from remotely sensed data quantitatively. For this, an accuracy assessment was performed using Kappa statistics. In the present study, the classification overall accuracy of land use reaches $88 \%$ and the values of kappa statistics range from 0.80 and 0.86 , respectively. The overall classification accuracy of the images yielded substantial-high Kappa statistics of $80 \%, 88 \%, 82 \%$, $82.41 \%$, and $87.76 \%$ for $1980,1990,2000,2010$, and the 2020 images, respectively. This is an indication of classification accuracy of moderately substantial to almost perfect agreement.

\begin{tabular}{|c|c|c|c|c|c|}
\hline $\begin{array}{l}\text { Class } \\
\text { Name }\end{array}$ & $\begin{array}{l}\text { Refere } \\
\text { nce }\end{array}$ & $\begin{array}{l}\text { Class } \\
\text { Name }\end{array}$ & $\begin{array}{l}\text { Refer } \\
\text { ence }\end{array}$ & $\begin{array}{l}\text { Class } \\
\text { Name }\end{array}$ & $\begin{array}{l}\text { Refere } \\
\text { nce }\end{array}$ \\
\hline \multicolumn{6}{|c|}{1980} \\
\hline $\begin{array}{l}\text { Water } \\
\text { body }\end{array}$ & 14 & 12 & 11 & $85.29 \%$ & $90.00 \%$ \\
\hline $\begin{array}{l}\text { Barren } \\
\text { land }\end{array}$ & 9 & 8 & 7 & $77.67 \%$ & $85.71 \%$ \\
\hline Urban & 11 & 11 & 10 & $90.91 \%$ & $90.91 \%$ \\
\hline $\begin{array}{l}\text { Agricultu } \\
\text { ral }\end{array}$ & 13 & 14 & 12 & $92.31 \%$ & $85.71 \%$ \\
\hline $\begin{array}{l}\text { Tree } \\
\text { cover }\end{array}$ & 10 & 9 & 9 & $90.00 \%$ & $100.0 \%$ \\
\hline Totals & 57 & 51 & 46 & & \\
\hline \multicolumn{3}{|c|}{$\begin{array}{l}\text { Overall Classification } \\
\text { Accuracy }=80.70 \%\end{array}$} & \multicolumn{3}{|c|}{$\begin{array}{l}\text { Overall Kappa Statistic }= \\
0.90\end{array}$} \\
\hline \multicolumn{6}{|c|}{1990} \\
\hline $\begin{array}{l}\text { Water } \\
\text { body }\end{array}$ & 7 & 13 & 5 & $71.43 \%$ & $38.46 \%$ \\
\hline $\begin{array}{l}\text { Barren } \\
\text { land }\end{array}$ & 11 & 10 & 10 & $90.33 \%$ & $100.0 \%$ \\
\hline Urban & 17 & 15 & 15 & $88.59 \%$ & $100.0 \%$ \\
\hline $\begin{array}{l}\text { Agricultu } \\
\text { ral }\end{array}$ & 9 & 7 & 6 & $77.11 \%$ & $66.29 \%$ \\
\hline $\begin{array}{l}\text { Tree } \\
\text { cover }\end{array}$ & 8 & 5 & 5 & $62.50 \%$ & $100.0 \%$ \\
\hline Totals & 50 & 50 & 26 & & \\
\hline \multicolumn{3}{|c|}{$\begin{array}{l}\text { Overall Classification } \\
\text { Accuracy }=88 \%\end{array}$} & \multicolumn{3}{|c|}{$\begin{array}{l}\text { Overall Kappa Statistic }= \\
0.91\end{array}$} \\
\hline
\end{tabular}

\begin{tabular}{|c|c|c|c|c|c|}
\hline \multicolumn{6}{|c|}{2000} \\
\hline $\begin{array}{l}\text { Water } \\
\text { body }\end{array}$ & 14 & 13 & 12 & $85.00 \%$ & $95.46 \%$ \\
\hline $\begin{array}{l}\text { Barren } \\
\text { land }\end{array}$ & 10 & 9 & 8 & $90.00 \%$ & $80.00 \%$ \\
\hline Urban & 17 & 15 & 15 & $88.00 \%$ & $\begin{array}{l}100.00 \\
\%\end{array}$ \\
\hline $\begin{array}{l}\text { Agricultu } \\
\text { ral }\end{array}$ & 9 & 7 & 7 & $77.00 \%$ & $\begin{array}{l}100.00 \\
\%\end{array}$ \\
\hline $\begin{array}{l}\text { Tree } \\
\text { cover }\end{array}$ & 8 & 5 & 5 & $62.50 \%$ & $\begin{array}{l}100.00 \\
\%\end{array}$ \\
\hline Totals & 50 & 50 & 26 & & \\
\hline \multicolumn{3}{|c|}{$\begin{array}{l}\text { Overall Classification } \\
\text { Accuracy }=82 \%\end{array}$} & \multicolumn{3}{|c|}{$\begin{array}{l}\text { Overall Kappa Statistic }= \\
0.92\end{array}$} \\
\hline \multicolumn{6}{|c|}{2010} \\
\hline $\begin{array}{l}\text { Water } \\
\text { body }\end{array}$ & 4 & 3 & 3 & $75.00 \%$ & $\begin{array}{l}100.00 \\
\%\end{array}$ \\
\hline $\begin{array}{l}\text { Barren } \\
\text { land }\end{array}$ & 13 & 12 & 12 & $92.97 \%$ & $\begin{array}{l}100.00 \\
\%\end{array}$ \\
\hline Urban & 37 & 32 & 31 & $83.78 \%$ & $96.88 \%$ \\
\hline $\begin{array}{l}\text { Agricultu } \\
\text { ral }\end{array}$ & 12 & 11 & 11 & $91.66 \%$ & $\begin{array}{l}100.00 \\
\%\end{array}$ \\
\hline $\begin{array}{l}\text { Tree } \\
\text { cover }\end{array}$ & 2 & 2 & 2 & $\begin{array}{l}100.00 \\
\%\end{array}$ & $\begin{array}{l}100.00 \\
\%\end{array}$ \\
\hline Totals & 58 & 58 & 42 & & \\
\hline \multicolumn{3}{|c|}{$\begin{array}{l}\text { Overall Classification } \\
\text { Accuracy }=82.41 \%\end{array}$} & \multicolumn{3}{|c|}{$\begin{array}{l}\text { Overall Kappa Statistic }= \\
0.54\end{array}$} \\
\hline \multicolumn{6}{|c|}{2020} \\
\hline $\begin{array}{l}\text { Water } \\
\text { body }\end{array}$ & 4 & 2 & 2 & $50.00 \%$ & $\begin{array}{l}100.00 \\
\%\end{array}$ \\
\hline $\begin{array}{l}\text { Barren } \\
\text { land }\end{array}$ & 3 & 5 & 1 & $33.33 \%$ & $20.00 \%$ \\
\hline Urban & 37 & 34 & 34 & $91.89 \%$ & $\begin{array}{l}100.00 \\
\%\end{array}$ \\
\hline $\begin{array}{l}\text { Agricultu } \\
\text { ral }\end{array}$ & 12 & 15 & 9 & $75.00 \%$ & $60.00 \%$ \\
\hline $\begin{array}{l}\text { Tree } \\
\text { cover }\end{array}$ & 2 & 2 & 2 & $\begin{array}{l}100.00 \\
\%\end{array}$ & $\begin{array}{l}100.00 \\
\%\end{array}$ \\
\hline Totals & 58 & 58 & 48 & & \\
\hline \multicolumn{3}{|c|}{$\begin{array}{l}\text { Overall Classification } \\
\text { Accuracy }=87.76 \%\end{array}$} & \multicolumn{3}{|c|}{$\begin{array}{l}\text { Overall Kappa Statistics }= \\
0.89\end{array}$} \\
\hline
\end{tabular}

Table 3. Theoretical error matrix of LULC classification for the year 1980-2020 


\section{CONCLUSION AND RECOMMENDATION}

The population increased three times during this period. This speedy population growth is the main factor of rapid urban expansion in the Lahore District. It is also found that no major change occurred in the area consisted of water bodies during this period. Satellite Remote Sensing (RS) data and Geographic Information System (GIS) abilities proved invaluable for appraising the LULC and LST in this study since this technique offers the ability to gather data over a large area simultaneously. In urban areas spanning several hundred square kilometers, it may not be feasible to gather LST in-situ measurements across the entire area.

The study shows that the ever-increasing encroachment of the city's newly developed agricultural land and green land over Lahore have accompanied general warming of the district's average LST over the past decade and that allowing the land vacant for years after clearing the agricultural fields for future urban expansion is a practice that has unwanted environmental effects. The recent COBID-19 pandemic has a massive global impact. The Lahore District also faced a strict lockdown situation, having the least vehicle exhausts and other human activities causing fewer emissions that upshot well for the environmental restoration. During those days, the spatial pattern of the LST shows that the natural habitat was reclaiming its position. Increasing more environmental issues and increasing the time span of the study would help determine a pivotal relationship between LST and LULC practices. Pattern for the year 2020 (figure 4.2 , e). Due to the complete lockdown situation globally, there were almost no to very little human activities in Lahore District as well. The emissions were very less, lowing the pollution, hence decreasing the LST spatially and higher temperature a degree lower.

To appraise the Spatio-temporal variation in LST between 2010 and 2020, we estimated the LST for the year 2018. It can be seen that the excessive construction in the Lahore District has led to temperature increases and decreasing green lands. In 2018, the changes in LULC have influenced the average temperature is shown in figure $(4.1, \mathrm{~d})$. From the analysis, it

was concluded that maximum temperature was increased in an urban area from 2000 to 2018 as compared to other land covers. In water bodies and trees, the minimum changes occur in the

land surface temperature of the study area. Greenery and agricultural land cover show also significant changes in surface temperature. The analysis and interpretation of land surface temperature indicate that major changes in land surface temperature occur from 1990 to 2020.

\section{REFERENCES}

Jarah, S. H. A., Zhou, B., Abdullah, R. J., Lu, Y., \& Yu, W. (2019). Urbanization and urban sprawl issues in city structure: A case of the Sulaymaniah Iraqi Kurdistan Region. Sustainability, 11(2), 485.

Akanwa, A. O., \& Joe-Ikechebelu, N. (2019). The Developing World's Contribution to Global Warming and the Resulting Consequences of Climate Change in These Regions: A Nigerian Case Study. In Global Warming and Climate Change. IntechOpen.
Khan, M. A., Khan, J. A., Ali, Z., Ahmad, I., \& Ahmad, M. N. (2016). The challenge of climate change and policy response in Pakistan. Environmental Earth Sciences, 75(5), 412.

Liu, Y., \& Jiang, Y. (2020). Urban growth sustainability of Islamabad, Pakistan, over the last 3 decades: a perspective based on object-based backdating change detection. GeoJournal, $1-21$.

Ding, H., \& Shi, W. (2013). Land-use/land-cover change and its influence on surface temperature: a case study in Beijing City. International Journal of Remote Sensing, 34(15), 5503-5517.

Sadiq Khan, M., Ullah, S., Sun, T., Rehman, A. U., \& Chen, L. (2020). Land-Use/Land-Cover Changes and Its Contribution to

Urban Heat Island: A Case Study of Islamabad, Pakistan. Sustainability, 12(9), 3861.

Hassan, Z., Shabbir, R., Ahmad, S. S., Malik, A. H., Aziz, N., Butt, A., \& Erum, S. (2016). Dynamics of land use and land cover change (LULCC) using geospatial techniques: a case study of Islamabad Pakistan. SpringerPlus, 5(1), 1-11.

Hussain, S., Mubeen, M., Ahmad, A., Akram, W., Hammad, H. M., Ali, M., ... \& Nasim, W. (2019). Using GIS tools to detect the land use/land cover changes during forty years in Lodhran district of Pakistan. Environmental Science and Pollution Research, 1-17.6

Alawamy, J. S., Balasundram, S. K., Hanif, A. H. M., \& Sung, C. T. B. (2020). Detecting and Analyzing Land Use and Land Cover Changes in the Region of Al-Jabal Al-Akhdar, Libya Using Time-Series Landsat Data from 1985 to 2017. Sustainability, 12(11), 4490.

Shakrullah, K., Shirazi, S. A., \& Sajjad, S. H. (2019). An Assessment of Land Use and Land Cover Changes In Lahore (Pakistan) and New Delhi (India) Using Geospatial Techniques. Pakistan Journal of Science, 71(4), 249.

Cengiz, A. E. (2013). Impacts of Improper Land Uses in Cities on the Natural Environment and Ecological Landscape Planning. In Advances in Landscape Architecture. IntechOpen.

Osborne, B. P., Osborne, V. J., \& Kruger, M. L. (2012). Comparison of satellite surveying to traditional surveying methods for the resources industry. Journal of the British Interplanetary Society, 65(2), 98.

Reis, S. (2008). Analyzing land use/land cover changes using remote sensing and GIS in Rize, North-East Turkey. Sensors, 8(10), 6188-6202.

Ali, S. S. F., Mehmood, S. A., Hassan, M., \& Latif, A. (2019, November). River Runoff Modelling Through Geospatial Techniques-A Case Study of Snow and Glacier Fed Astore River Basin, Northern Pakistan. In 2019 Sixth International Conference on Aerospace Science and Engineering (ICASE) (pp. 1-12). IEEE.

Chengqi, C., Bin, L., \& Ting, M. (2003). The application of very high resolution satellite image in urban vegetation cover 
investigation: a case study of Xiamen City. Journal of Geographical Sciences, 13(3), 265-270.

Deng, Z., Zhu, X., He, Q., \& Tang, L. (2019). Land use/land cover classification using time series Landsat 8 images in a heavily urbanized area. Advances in Space Research, 63(7), 2144-2154.

Luna, M. I. R. (2006). High-Resolution Satellite Data for MappingLanduse/Land-cover in the Rural-Urban Fringeof the Greater Toronto Area.

Sillmann, J., Thorarinsdottir, T., Keenlyside, N., Schaller, N., Alexander, L. V., Hegerl, G., ... \& Zwiers, F. W. (2017). Understanding, modeling and predicting weather and climate extremes: Challenges and opportunities. Weather and climate extremes, 18, 65-74.

Aik, D. H. J., Ismail, M. H., \& Muharam, F. M. (2020). Land Use/Land Cover Changes and the Relationship with Land Surface Temperature Using Landsat and MODIS Imageries in Cameron Highlands, Malaysia. Land, 9(10), 1-23.

Pal, S., \& Ziaul, S. K. (2017). Detection of land use and land cover change and land surface temperature in English Bazar urban centre. The Egyptian Journal of Remote Sensing and Space Science, 20(1), 125-145.

Liu, W., Feddema, J., Hu, L., Zung, A., \& Brunsell, N. (2017). Seasonal and diurnal characteristics of land surface temperature and major explanatory factors in Harris County, Texas. Sustainability, 9(12), 2324.

Hofmann, G. E., \& Todgham, A. E. (2010). Living in the now: physiological mechanisms to tolerate a rapidly changing environment. Annual review of physiology, 72, 127-145.

Weng, Q., Lu, D., \& Schubring, J. (2004). Estimation of land surface temperature-vegetation abundance relationship for urban heat island studies. Remote sensing of Environment, 89(4), 467483..

Wang, R., Hou, H., Murayama, Y., \& Derdouri, A. (2020). Spatiotemporal analysis of land use/cover patterns and their relationship with land surface temperature in Nanjing, China. Remote Sensing, 12(3), 440.

Xiao, R., Weng, Q., Ouyang, Z., Li, W., Schienke, E. W., \& Zhang, Z. (2008). Land surface temperature variation and major factors in Beijing, China. Photogrammetric Engineering \& Remote Sensing, 74(4), 451-461.

Saleem, M. S., Ahmad, S. R., \& Javed, M. A. (2020). Impact assessment of urban development patterns on land surface temperature by using remote sensing techniques: a case study of Lahore, Faisalabad and Multan district. Environmental Science and Pollution Research, 27(32), 39865-39878.

Punjab Portal. Government of Punjab. Retrieved May 14, 2012.

Nasar-u-Minallah, M. (2019). Retrieval of land surface temperature of Lahore through Landsat-8 TIRS data. International Journal of Economic and Environmental Geology, 10(1), 70-7.
Saleem, Muhammad Sajid, Sajid Rashid Ahmad, and Muhammad Asif Javed. "Impact assessment of urban development patterns on land surface temperature by using remote sensing techniques: a case study of Lahore, Faisalabad and Multan district." Environmental Science and Pollution Research 27, no. 32 (2020): 39865-39878.

Ather Ashraf, M. I., \& Shahbaz, A. (2015). Protecting agricultural land in developing countries: A case study from Lahore, Pakistan. International Journal of Advanced Remote Sensing and GIS, 4, 1181-1194.

Liaqut, A., Younes, I., Sadaf, R., \& Zafar, H. (2019). Impact of urbanization growth on land surface temperature using remote sensing and GIS: a case study of Gujranwala City, Punjab, Pakistan. International Journal of Economic and Environmental Geology, 44-49. 